\title{
Research on Second Language Learners' Obstacles to English Pronunciation Learning and Countermeasures*
}

\author{
Jingxin Wang \\ Foreign Language School \\ Jilin Institute of Chemical Technology \\ Jilin, China 132022
}

\begin{abstract}
English pronunciation learning has long been regarded as a complex problem. There are many Factors affecting English pronunciation learning. This paper presents three reasons: Insufficient knowledge of English phonology and phonetics, negative transfer of Chinese to English and affective factors and tries to present possible solutions.
\end{abstract}

Keywords-English pronunciation; learning obstacle; negative transfer of mother tongue

\section{INTRODUCTION}

As the most widely used language in the world today, English plays an extremely important role in politics, economy, diplomacy, military, science and technology, trade, culture, education and other fields. As an important communicative tool, oral English is frequently used in international communication activities such as business negotiation, cultural exchange, science and technology conference. Oral English communicative competence has become an important criterion for measuring contemporary talents. Good oral English competence is one of the important qualities of talents in the 21 st century. With the acceleration of economic globalization and internationalization, China is constantly in line with the international standards in various fields, and international exchanges are becoming more and more frequent. In the current international context, the need for international communication has led to an increasing demand for oral English talents, and higher requirements have been put forward for the oral English talents.

Pronunciation is the basis and premise of spoken language, and correct pronunciation is the prerequisite for oral communication. Pronunciation affects both the reception of information and the transmission of information. A person's poor pronunciation makes it hard to hear correctly, and it is difficult for what is said to be conveyed accurately, which seriously hinders the smooth communication. Therefore, the correct mastery of phonetics plays an important role in oral communication, which is

*This paper is one of the research results of Research on Pronunciation Learning Strategies of English Majors [2018039] (A Science Research Project in Jilin Institute of Chemical Technology) directly related to the fluency of language communication and the accuracy of thought expression, and is the key to the success of communication. Language consists of three parts: speech, semantics and grammar, among which speech is the most basic and most important element. Any language is produced by sound language first, and then the text language and learning language should start from sound. To learn spoken English well, we must lay a good and solid foundation for English pronunciation.

It is desirable for English learners to speak fluently like native speakers. As is known, the effectiveness and success of communication is affected directly by one's pronunciation, but it is an undeniable fact that a great number of Chinese students don't have standard pronunciation. There are a variety of obstacles for Chinese English learners.

\section{ChINESE ENGLISH LEARNERS` LEARNING OBSTACLES}

It is difficult for Chinese learners to master the phonetic system of English. According to the survey conducted by the author, the causes of phonetic errors made by English majors can be summarized as follows:

\section{A. Lack of Knowledge in English Phonology and Phonetics}

In the process of English language acquisition, for lack of sufficient knowledge of phonology and phonetics, more and more Chinese students will make phonetic mistakes gradually.

The accent, rhythm and intonation are really a whole because they are so closely linked that they form a continuous flow of English. Although some Chinese learners can pronounce individual sound accurately, they also need to understand how they are combined in order to communicate with others in an effective way. To understand the prosodic features of continuous speech flow is the basis of English phonetic learning, which is essential for the communicator's understandability. In standard English pronunciation, the correct stress, rhythm and intonation are much more important than English phonemes, which is being recognized by more and more people. However, it should also be admitted that it is difficult to teach and learn 
stress, rhythm and intonation, because native speakers of English always change their patterns according to different contexts. In fact, they always work together, thus laying a good foundation for oral English. If a speaker wants to understand spoken English and master acceptable English pronunciation, he must understand its features.

\section{B. Negative Transfer of Mother Tongue}

When people learn a foreign language, they can usually master the standard pronunciation quickly in their childhood, but this ability will be weakened with age. For the most part, the mother tongue can be an annoying distraction in learning a foreign language. Of course, there are many factors that affect English phonetic acquisition--cognitive development, language commonality, psychological status and so on. However, as far as second language acquisition is concerned, phonetics will be particularly disturbed by the mother language. To some extent, all the different phonetic errors in the speech test can be attributed to the negative transfer of the learner's mother tongue. Language transfer is a common phenomenon for language learners. It is the influence of one language on another. It is inevitable that language learners are influenced by their mother tongue in their second language acquisition. They may bring their habit and knowledge of their mother tongue's pronunciation, grammatical structure.

It is rarely difficult for English learners in China to learn those sounds in both English and Chinese. The most difficult sounds for them to pronounce are those that are not included in their native language or dialect, or those that are similar to their native language or dialect but are actually not the same. Many learners have speech errors caused by negative transfer of the mother tongue, both in segmental phonemes and in supra-segmental phonemes. [3] For example, many students in the phonemes tend to mispronounce the sounds $[\theta]$ and $[ð]$ as $[\mathrm{s}]$ and $[\mathrm{z}]$. They can't pronounce them correctly because these sounds don't exist in Chinese. When some learners pronounce, they often try to replace the standard English phonemes with the similar sounds in their mother tongue. For example, Chinese people often use "zi" in Chinese instead of English consonant [z]. [4] Similar sounds do exist in both languages, but they are pronounced in very different places and in very different ways. Native speakers of English feel strange and uncomfortable while listening to sounds uttered in this way.

The negative transfer of the mother tongue has a greater impact on the learner's speech in the supra-segmental phonemes. Many learners place too much emphasis on vowels when they speak English as they do in Chinese. [5] But compared with Chinese, English words start with a more stressed consonant sound. In terms of sentence stress, some students are influenced by the way Chinese characters are pronounced, assigning the same time and stress to each word in a sentence. In terms of intonation, problems caused by negative transfer of mother tongue still exist. In Chinese, the tone of a sentence depends on the tone of each word in the sentence, so the tone cannot be changed at will. [6] To a large extent, learners are influenced by the speaking habits of their native language. When they speak English, their intonation is relatively flat, with little fluctuation. And quite a few students find it difficult to read liaison, which is rarely used in Chinese.

Although it is true that the negative transfer of mother tongue can account for some learners' pronunciation problems, but this is not the only factor affecting the phonetic learning. There are also many problems that are not caused by the difference between English and Chinese.

\section{Affective Factors}

After investigation, the author believes that learners' self-consciousness plays an important role in the process of English phonetic learning. [7] On the one hand, they are not confident in their own pronunciation, because the evaluation of students' pronunciation is often not as important as other English tests. On the other hand, Chinese English learners tend to be more modest and shy, unwilling to show themselves in public. Therefore, they do not have a clear idea of how much they can achieve in phonetic learning.

In order to communicate with the target language, learners need to respond quickly and face the evaluation of others. In this situation, they are likely to feel anxious. Motivation and learning anxiety also have an impact on learners' speech learning. A Study has shown that motivation and attitude are important factors influencing learners' success in learning a foreign language. [8]

Psychological factors are often ignored in phonetic teaching. The way an individual speaks is closely related to the emotions and purposes of the individual in a particular situation. If a learner of a second language recognizes English as his native language and sees himself as the same as the other person, he may speak like the native speaker. On the contrary, if learners adhere to their social status and the sense of identity of culture in order to be attached to certain groups, they often consciously or unconsciously keep a kind of foreign accent. Therefore, many researchers of phonetic teaching advocate that phonetic teaching should be combined with learners' value system, personal attitude and their social and cultural schema.

\section{ANALYSIS OF TEACHING COUNTERMEASURES}

\section{A. Emphasizing English Phonetic Knowledge in English Phonetic Teaching}

Traditional phonetic teaching focuses on isolated phonemes. Therefore, although the learners in the context of this education can accurately utter individual phonemes, they can't pronounce words and sentences correctly. In fact, the isolated phonemes are extracted from the real speech flow, and the dialogue in the real situation will definitely involve the problem of adjacent sounds. Through speech analysis, we know that the same sound can be pronounced in many ways. Therefore, teachers should teach students about the phonemic variation. The phoneme variant is the different variation form of the same phoneme, which is the specific embodiment or specific representative of phoneme in the specific phonetic context. [9]Not every phoneme has its distinct phoneme variant, but there are slight differences 
in the same phoneme pronunciation in the flow of speech. In order to communicate well, learners should have a good knowledge of related phonemic variants.

Chinese learners' mother tongue is Chinese, and Chinese is a tonal language. Under the influence of their mother tongue, they often make mistakes in English accent. In order to better understand and practice English stress patterns, emphasis should be placed on English stress to make it the basis of English phonetic teaching and training. Stress plays a crucial role in the way English is spoken and is the basis of rhythm and intonation. Therefore, teachers of English phonetics should make students clearly understand the basic function of information transfer.

\section{B. Clearly Distinguishing Between English and Chinese Phonetic Systems}

There is no doubt that learners' speech mistakes can be attributed to the interference of their mother tongue. It is generally accepted that the comparative analysis of learners' mother tongue and second language is beneficial to their language acquisition. In the process of foreign language learning, it is necessary and crucial for learners to realize the differences between English and Chinese and make a conscious comparison. Most English teachers in China are native speakers of Chinese, who are more aware of the differences between Chinese and English.

The teacher should make an all-round comparison of English and Chinese phonetic system from the phoneme, syllable, stress, rhythm, intonation, speech flow change and so on to let the students know the similarity and difference between them. English belongs to the Indo-European language family, while Chinese belongs to the Sino-Tibetan language family. In terms of syllable structure, the syllables in English are mostly closed syllables ending in consonants, while the open syllables ending in vowels are in the minority. Most syllables in Chinese begin with consonants and end with vowels. English syllables may have consonant groups at the beginning or at the end. There is usually only one consonant at the beginning or end of a Chinese syllable. In stress and rhythm, English is syllable-timed, while the Chinese language is punctuated by stress. In terms of tone and intonation, English is a kind of intonation language, while Chinese is a tonal language in which every word in the sentence has a fixed tone and the sentence tone is only adjusted on the last syllable at the end of the sentence, so the tune ups and downs of the whole sentence is with little fluctuation range and without wide pitch changes.[10]In terms of language flow and phonological changes, such as English pronunciation phenomena such as linking, assimilating, weakening, voicing, ellipsis, etc., are also absent in Chinese. English is a continuous sound, which can achieve an uninterrupted transition, while Chinese is staccato in which it is not easy for syllables to link with adjacent syllables.

On the analysis of the pronunciation errors caused by negative transfer of mother tongue, teachers should not only compare them, but also tell students the causes of problems are the different ways of pronunciation in English and
Chinese languages so as to teach them how to use the language contrast method to solve the problems. For example, when teaching the two phonemes $[\theta]$ and $[ð]$, the teacher can first tell the students that they do not exist in the Chinese phonetic system, and that $[\theta]$ is not the same as [s], and that $[ð]$ is not $[\mathrm{z}]$. Then the teacher can explain and show the correct pronunciation to the students. In fact, compared with phonemes, Chinese students have more problems with the supra-segmental phonemes such as stress, rhythm and intonation. Therefore, it is a very important task for teachers to find out students' pronunciation problems, analyze their causes and find out countermeasures. Description and comparison play a greater role in this task than imitation.

\section{Adopting Learner-centered Teaching to Strengthen the Role of Emotional Factors}

The purpose of phonetic learning is to communicate effectively, that is, to cultivate the satisfactory pronunciation level of learners in practical communication. Therefore, phonetic teaching should aim at satisfying learners' actual communicative ability and cultivating their comprehensible oral English. The new concept of pronunciation teaching is that we should develop learners' comprehensive qualities, including listening comprehension, communication, selfmonitoring, adjusting strategies and even confidence. [11]

When teachers use communicative methods in phonetic teaching, they should be clearly aware of the need to teach students the application of practical phonetic skills. In addition to teaching segmental phonemes like phonemes, teachers should also create a certain atmosphere for students to learn phonetics in authentic communication. Moreover, phonetic teachers should also provide a comparison between different features of English and Chinese, between isolated sounds and those actually produced in the speech flow. Only in this way can students greatly improve their ability to apply phonetic knowledge to practical communication.

Teachers should bear in mind that the classroom teaching information consists of content and emotional aspects of content, so it is necessary to pay attention to and respect for the needs of the students' emotions so as to optimize classroom teaching effects. Phonetic courses are generally offered as a basic course for freshmen. As new college freshmen, they often feel a certain degree of anxiety. The phonetic teacher's standard pronunciation, intonation and gracious manners are able to relieve the anxiety of freshmen to a certain extent and stimulate their interest in English learning.

There is a strong practicality in phonetics class, and often students need to practice. In the classroom practice, the teacher must take into account the students' emotional factors. When the teacher makes a careful evaluation of students, the negative language should be used with caution. The teacher should properly enlarge their advantages and use positive language to encourage students as much as possible. Don't interrupt a student to point out a mistake in pronunciation. When correcting a mistake, the teacher 
should take care of the student's self-esteem. If possible, try to use the method of recasting the mistake afterwards.

In English phonetic class, teachers should pay attention to the interaction with students, so that students can participate in phonetic teaching. Participation in English phonetic class is no longer limited to listening and imitating. Students should participate in the learning process. Highlevel participation can cultivate their sense of communication and develop their own language learning strategies. On the other hand, the role of the phonetic teacher should be changed from "commander" to "guider", [12] who guides students to improve their pronunciation level through sound demonstration and strategy sharing. Teachers should retreat to a non-dominant position in the teaching process and encourage students to play a greater role in communicative learning. The teacher acts as a "pronunciation coach", providing demonstration, feedback and advice. Effective English phonetic class requires the participation and efforts of both teachers and students.

\section{CONCLUSION}

To sum up, there are many obstacles to English phonetic learning for Chinese English learners, including cognitive factors and emotional factors. After analyzing the causes, the author attempts to put forward some teaching strategies, hoping English phonetics teachers can improve teaching ideas, use relevant strategies in the teaching and improve English phonetics teaching effect.

\section{REFERENCES}

[1] Luo han, Zhang Wenzhi, Analysis of college students' English phonetic Errors [J]. Chinese University Teaching, 2006 (7).

[2] Fang Lan. Factors affecting foreign language pronunciation Learning [J]. Journal of Foreign Languages, 2007(4).

[3] Pan Wenguo. Comparative Essentials of Chinese and English [M]. Beijing Language and Culture University Press, 2004.

[4] Wei Zhicheng. Comparative introduction to Chinese and English [M]. Shanghai foreign language Education Press, 2003.

[5] Ellis, Rod. Understanding Second Language Acquisition [M]. Shanghai foreign Language Education Press, 1999.

[6] Odlin. T. Language Transfer [M]. Shanghai foreign Language Education Press, 2001.

[7] Wang Chuming. English phonetic self-concept and actual English phonetic Level [J]. Foreign Languages, 2004,(5).

[8] Shao Ruizhen. Education Psychology [M]. Shanghai foreign Language Education Press, 2002.

[9] Zhang Fengtong. English phonetics and Phonology [M]. Sichuan University Press, 2004.

[10] He Shanfen. A comparative study of English and Chinese Language [M]. Shanghai Foreign Language Education Press, 2005.

[11] Wen Qiufang, Wang Lifei. A review of various factors influencing the operation of foreign language learning Strategies [J]. Foreign Language and Foreign Language Teaching,2004,(9).

[12] Zhang Keqin. Study on English phonetic learning Strategies [J]. Journal of Yunnan Normal University, 2002,(6). 